\title{
Performing Arts - How do we Survive the Pandemic?
}

Andrei BADIN ${ }^{1}$

\begin{abstract}
All cultural services have been suffering in the past year. Since the start of the pandemic all artists have felt the pushback from the COVID 19 pandemic. We analyze the pandemic impact over cultural services in Romania by observing data and also discussing with entrepreneurs or artists about the impact that the pandemic had in their lives. Within this paper we address some of the most important aspects of cultural services, artists and hardships. Social distancing has rendered all cultural events locations obsolete because they are no longer profitable. The marketing mix used for services during the pandemic has suffered alteration. A few months the cultural life of Bucharest very nimbly managed to engage their target audience with the help of social media platforms - YouTube, Facebook and Instagram. This choice may have stopped some of the bleeding and may have given the artists the opportunity to do the activity they love.
\end{abstract}

Keywords: cultural services, services marketing, theater, live concerts, pandemic, marketing mix

JEL classification: M14, M21, M31

DOI: $10.24818 /$ RMCI.2021.1.87

\section{Introduction}

The Pandemic of Covid 19 put a lot of things into perspective, especially the services industries. A lot of business suffered losses: restaurants, shops and brands present in shopping malls and especially the family owned businesses. The state managed to supply better legislation and procedures in order to help and offer a relief for the fiscal burden that companies are under. There have been many discussions about the social effects of pandemic from a relational point of view and also from a financial point of view by analyzing the new consumption habits of people. The beginning of 2020 has been very difficult, abruptly changing people's life's, disrupting the "normal" life and creating an alternate normality in which humans, companies and state representatives scrambled to understand the risks and dangers of not adapting to the new normal.

There have been many discussion all through the year about the main industries affected by the pandemic. It is logical to say that all aspects of life have been affected and it will take a fair amount of time to return back to a closer

\footnotetext{
${ }^{1}$ Badin Andrei, Bucharest University of Economic Studies, Email Address: badin.andrei@gmail.com
} 
normality like before. It is clear and obvious to state the fact that this is the new normal and a world without masks is very far from present time.

European Union has offered a total of 4.2 trillion euros as a response to the Coronavirus pandemic and this has been very helpful for all states in the EU. The relief helped a lot of people that discovered from one day to the other that they lives have been changed drastically. From being laid off to being unable to making rent, a lot of people suffered from the financial implications of the Coronavirus pandemic. Furthermore we have to take into consideration another relevant impact, the psychological one of isolation oneself from human contact for a minimum of one month - April, when Romania was in total lockdown. A lot of companies managed to displace daily activity from office to home and encouraged employees to work from home, even giving them money to make acquisitions for the home office (Uipath is a good example of helping employees and having all they need in order to feel comfortable at home from an office perspective).

It is very important to understand as well the impact of the pandemic in children and young people. Work from home is a blessing. In October a new legislation was issued that enforces work from home for all employees that are not dependent on leaving their own homes. This is a very good measure taking into consideration the fact that kindergartens, schools and universities are closed for students. Before this legislation, the parents were facing a very difficult choice: where to leave the children while they were at work? This is why the pandemic raised many problems that returned with many questions, some of are not even possible to answer.

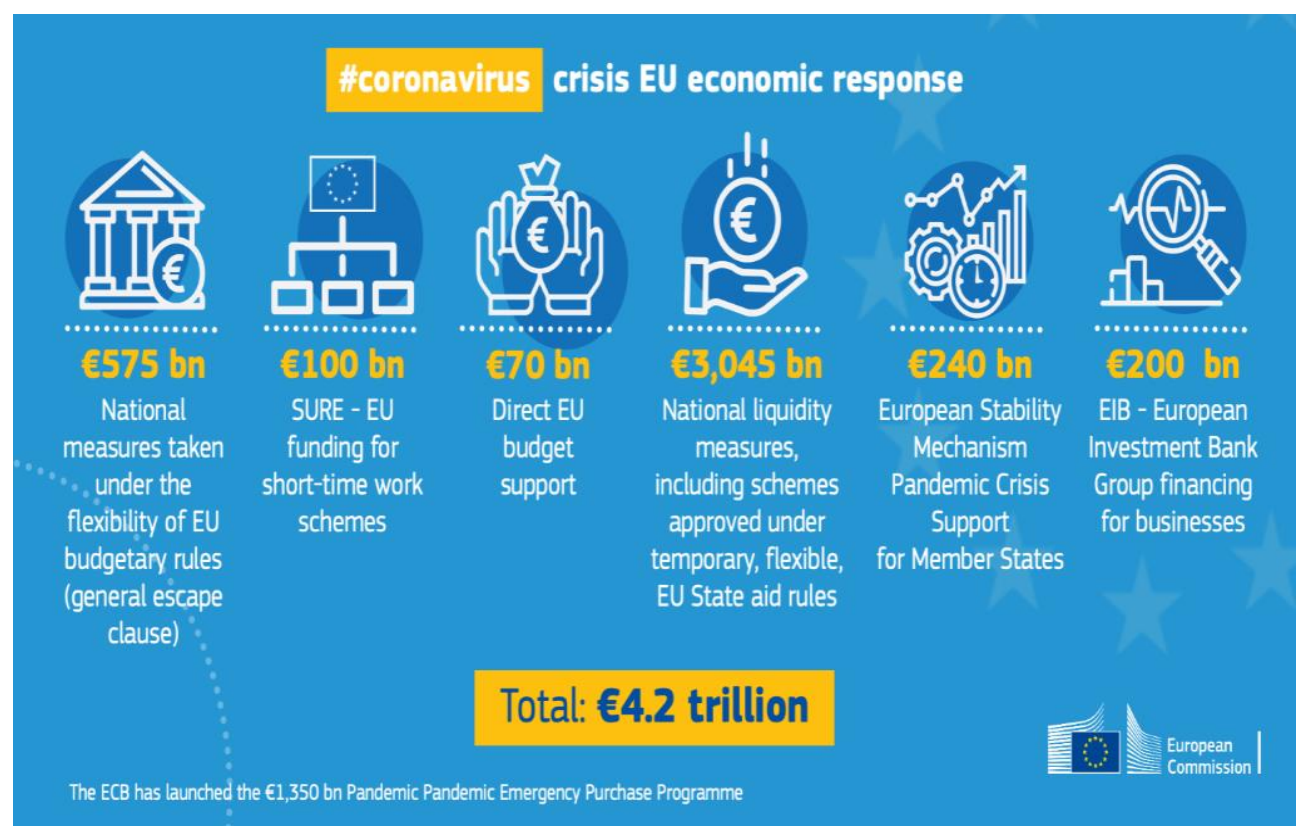

Figure 1 EU economic response to pandemic 
It is interesting to observe the way in which the performing arts managed to survive in this time. It is important to note the fact that the cultural strategy of Romania is based on the goals and strategies established by the European Union and UNESCO (Mucică et al., 2014). It is interesting to see what the main goals were and how they might have changed this year: young people, digitizing cultural resources, consumption, cultural offer and export diversification.

Cultural services, especially the performing arts, are not very easy to position in the marketing with all of the variables that exist, from personal preferences to marketing mix. So, it is easy to understand how the pandemic managed to push artists and culture entrepreneurs into a sprint of understanding and adapting on the go to a totally new situation. One important aspect is the fact that a lot of cultural entities have used and employed in their best interest the digital environment so the pivot towards this new reality was not really that difficult. This pivot was one of the most important steps taken by them because without it, a lot of people would have been left without their passion and occupation. It is indeed difficult to engage with the public through social media or platforms but it is not impossible.

\section{State of the art}

Very important in understanding what the performing arts went through this time is to see how the marketing mix works. There are seven elements: the communication, the cultural product, the price, the distribution, the personnel, tangibility and service (Jimenez \& Gervilla, 2011).

The concept of cultural product is analyzed from a double perspective, both from the point of view of the artist or creative team and from the point of view of the consumer (Laczniak in Cuadrado and Deseais, 2000). The broad concept of cultural product encompasses three components: the core product - the artwork, peripheral services or related (associated) services - and the value the consumer attributes to the product or the evaluation of the benefits obtained from it (Cuadrado and Deseais, 2000).

Marketing services in the performing arts must find a balance between consumer needs and respect for artistic integrity (Dawson, Scheff, \& Kotler in Cuadrado and Deseais, 2000). A model that emerged after the 2000s proposes a minimal product orientation by applying the post-production marketing mix (Colbert and Cuadrado in Flories et al., 2010). In this case, the cultural product is not influenced, the marketing teams only establish the price, the distribution method and the communication strategy. It is important to note that at the time Colbert and Cuadrado signed this article, marketers did not seek to meet a particular market need, but rather to discover potential consumer segments (Colbert and Cuadrado, 2003). The desires and motivations of the public also determine the rest of the elements of the marketing mix, designed to attract the attention of the target audience (Cuadrado and Deseais, 2000).

89 Review of International Comparative Management

Volume 22, Issue 1, March 2021 
How do we treat emotions within online? Emotional value is very importance and is the bedrock of any art. Furthermore emotional value gives economic value to the art product and it is directly proportionate (Vukovic în Cetină et. all., 2019). One way of achieving this is to employ the value of "cocreation" that gives providers the opportunity to expand their market, diversifying the activities through which potential customers have the opportunity to realize their own value (Gronroos în Cetină, 2019). This effort brings direct benefits at the stage when the consumer evaluates the service. Interactive activities can influence how consumers appreciate the value of the service.

Taking into consideration these aspects, cultural entrepreneurs and artists managed to pivot towards online with the help of social media and streaming platforms as: Facebook, Instagram and YouTube. Many entrepreneurs started creating cultural activities in public locations where there was a lot of space for people and not put anyone in danger. The movies drive through was created in Băneasa and Coletina by two entrepreneurs that understood the need of people to watch the movies with other people but from the safety of their own house: they offered a pseudo human interaction and movie.

Cultural entrepreneurs know that people are very subjective and choices are not made only by rational thinking, so this was also a very difficult variable to manage when exploring the digital opportunities. Many cultural entities created live performance streaming. Because of the pandemic, theaters had a restricted number of participants rendering all cultural activities unprofitable. The National Opera House created live streaming sessions as well. Children's theaters managed to go online on Facebook as well as the National Theater of Bucharest and stream performances for everybody. Most of the distribution was free, very few cultural activities were pay to watch. Some theaters and orquestras set up a very interesting approach with their artists, performing on stage in front of just cameras and live streaming through Facebook or YouTube.

They marketing mix suffered modifications, but not very big. In the center of the marketing mix, entrepreneurs and artists have placed the consumer. One hand, this is a solid approach and the other hand it should be paired up with a very high quality service or cultural product. In this circumstance, the consumer will feel safe in the comfort of his own home, will be happy and eager to regain the feeling of normality from before the pandemic. The consumer is a special category, analyzed extensively and segmented according to countless criteria, but especially according to needs and requirements. Richard Paterson makes a first distinction between "omnivorous" consumers (people interested in a wide range of cultural services) and "univores" (people who focus on a particular form of artistic service, such as theater) (Thorsby, 2010). Throughout the pandemic, from the perspective of entrepreneurs, everybody wants to participate in any kind of event that entails social interaction. Main reason for this is the fact that social gatherings and meatus are not advised and after months of lack of human interaction, people feel the need to explore new ways of interacting with other people. In this aspect, cultural entities have gained a lot of traction in online. Some examples are: artists who give 
concerts from their own home, museums give virtual tours, theaters, operas and orquestras offer live streaming and some visual artists started creating content and step-by-step guides for people that are interested in photography, painting or photo editing.

How has cultural policy changed with the pandemic?

The European Union is supporting the cultural efforts of countries, and one of the most interesting is the one made by the EIF (European Investment Fund) and Raiffeisenbank that signed a guarantee agreement at a value of 10 million EUR. This sum is intended to be allocated to banks that in return will offer it as credit (cashflow) for companies that need the capital in order to continue and offer services or goods to customers. This agreement provides the credit lines or loans with much better terms and conditions: interest rates, liquidity of the company and much faster terms of engagement. Raiffeisen bank offers a much faster approach in offering these credit lines and they simplified contracts, terms, agreements, fixed interest rates in some cases and fiduciary collateral. The full press release:

"On 6 October, the European Investment Fund and Raiffeisenbank signed a guarantee agreement worth EUR 10 million to support small and medium-sized private and public enterprises in the cultural and creative sectors in Bulgaria. The agreement provides for loans with more favorable terms and conditions to small and medium-sized enterprises affected by the coronavirus crisis, thus helping to maintain employment. In addition, on 14 October, thanks to a guarantee of EUR 6 million from the European Investment Fund, support was also allocated to small and medium-sized enterprises in the cultural and creative sectors in Estonia, Latvia, Lithuania and Finland. This guarantee is the first operation of the Guarantee Mechanism for the cultural and creative sectors in these countries and was granted to the Estonian financier Finora Capital, a fully digital alternative financial company. The system facilitates companies' access to more affordable credit and allows Finora Capital to develop a new product that meets the specific needs of small and medium-sized enterprises in the cultural and creative sectors, to develop skills in financing the cultural and creative sectors and to be expanding into new markets. The agreements were supported by the Commission's Guarantee Mechanism for the cultural and creative sectors and by the European Fund for Strategic Investments.” (https://ec.europa.eu/info/live-work-travel-eu/coronavirusresponse/jobs-and-economy-during-coronavirus-pandemic_ro)

The creative industries are continuing to grow according to some intermediate European Union statistics (Eurostat, 2020). The growth in creative industries arts is being driven by digital environment: social media, social platforms and online payments (Grone \& Acker, 2015). In this time it is very important to use all of the benefits on online and digital marketing in order to obtain a larger audience. Technically, there are no limitations to the number of spectators you can have so it would be a wise strategy to develop an own streaming platform by each entity.

91 Review of International Comparative Management

Volume 22, Issue 1, March 2021 
It is very interesting to see the take of Romania on the supporting of cultural efforts by the EU and how they managed to create a state aid scheme in 5 steps or measures. The state considered targeting non-governmental organizations and companies, small and large, with this program. For public owned entities they are offering an extra budget in order to maintain and invest in culture consumption. Furthermore, according to NIS it is important to note the fact that there are the following categories of public entertainment institutions (NIS, 2020):

1. Dramatic - 64 units in 2017

2. Dolls and puppets - 29 units in 2017

3. Works - 9 units in 2017

4. Street and operetta music - 6 units in 2017

5. Philharmonic and symphony orchestras - 24 units in 2017

6. Folk orchestras - 11 units in 2017

7. Other types of cultural units - 87 units in 2017

8. Circus - 1 unit in 2017

In 2018, the National Institute of Statistics registered 248 performance

units

It is also very important to take into consideration the fact that there are no significant fluctuations in the staff employed in the public institutions, in 2011 there were 11,182 employees, and in 2018 - 12,817 employees.

The aid scheme is offered to companies that have carried out activities in the last two years. An activity report must be made by the legal representative of the entity/applicant and their core activity should be in one of the following fields:

- Performing arts: theater, music and dance;

- Visual arts: painting, sculpture, film and photography;

- Heritage;

- Literature: books;

- Audio-visual;

- Cultural education.

Very important is the fact that the entities must be registered by the time they submit the inquiry in the Register of Cultural Sector administrated by the National Institute for Cultural Research and Training (INCFC), an institution that is part of the Ministry of Culture.

After understanding the prerequisites to apply for this aid scheme, the entities will have to see exactly in what measures they fit in. The measures have been developed based on the core cultural activity of the potential applicants:

1. The first measure is created for the performing arts field for cultural operators who have NO income from ticket sales. There is at the disposal of cultural entities, small or large, of micro grants equivalent in RON of the amount of maximum 4.000 EUR per beneficiary of state aid;

2. The second measure is created for organizing cultural festivals. For the cultural operators who organized a cultural festival with ticket sale the maximum value of state aid is the RON equivalent of $25 \%$ of the gross value of tickets sold at the 2019 edition of the festival, but not more than 800,000 euros; 
- The thirds measure is created for cultural operators that organized cultural events in 2019 and have revenues from tickets sold.

- Musical events and stand-up comedy events:

- Between 1 - 10 events organized in 2019 - the maximum value of state aid is the equivalent in lei of $5 \%$ of the gross value of tickets sold at events organized in 2019, but not more than 800,000 euros;

- Between 11 - 50 events organized in 2019 - the maximum value of state aid is the RON equivalent of $7 \%$ of the gross value of tickets sold at events organized in 2019, but not more than 800,000 euros;

- Over 50 events organized in 2019 - the maximum value of state aid is the RON equivalent of $9 \%$ of the gross value of tickets sold at events organized in 2019, but not more than 800,000 euro.

- Events from cultural fields other than music and stand-up comedy:

- The maximum value of state aid is the RON equivalent of $50 \%$ of the gross value of tickets sold at events organized in 2019, but not more than 800,000 euros.

- The fourth measure is represented by grants for bookstores:

- The maximum value of state aid is the RON equivalent of $25 \%$ of the gross value of book sales in 2019 , but not more than 800,000 euros.

- The fifth measure is represented by grants offered for publishing houses. The maximum value of state aid is the RON equivalent of $25 \%$ of the gross value of direct physical book sales in 2019, but not more than 800,000 euros.

There is a pre-registration stage that will last for one week. This week is used to assess the budgetary impact of the state aid scheme to support the cultural industry in an efficient and effective way so that they allocated budget will be sufficient. After the impact study, the elaboration of the normative act related to the State Aid Scheme will be put into public consultation. For the moment the estimated deadline for operationalizing the scheme will be the beginning of 2021 with an estimated budget of 100 MIL EUR (http://www.cultura.ro/100-milioanede-euro-pentru-sectorul-cultural-prin-schema-de-ajutor-de-stat).

The state aid scheme is a good approach of investing in the cultural industry, not only saving people's jobs but also creating new opportunities for companies to develop and diversify their portfolios of cultural services.

Another step taken by the state was for artists that had copywriting contracts before the pandemic to apply for unemployment. This was a very important step taken by the state in order to protect the artists and their livelihood.

\section{Methodology Research}

Establishing the current "status-quo" has been very important in order to better understand the existing situation. Moving forward we reached out to artists and cultural entrepreneurs to see what their opinion is about the pandemic, the new normal and the implication of the state in helping them. Seeing how this situation is

93 Review of International Comparative Management

Volume 22, Issue 1, March 2021 
very dynamic and changing from a week to another it was very important to understand the way in which people adapted to this new dynamic normality.

The first step was to identify cultural entities or people that are involved in creating cultural events, especially in the performing arts field: theater, dance, music etc. Most of the artists or managers have had a difficult year, managing the pandemic situation, balancing the expectations of the public regarding cultural preferences and needs that have changed because of social distancing and also taking into consideration the fact that the power of buying has lowered. All of these variables have determined artists and managers of cultural entities to rethink and reshape the foundation of creating and promoting cultural events. Many have taken into consideration creating e-meetings or e-events through the help of digital platforms to satisfy the need of social behavior and collective emotion/satisfaction.

Artists and managers alike have a high respect and love for the art they are providing. After come a multitude of economic and social variables. The pandemic managed to move the passion towards the target audience more than before. The main reason for this is distance and the need to make their art more available to the consumer and open many more ways of direct communication with artists or cultural entities.

The main objective of the study is to better understand the ways in which cultural entrepreneurs and artists have changed their approach to selling their cultural products.

The hypotheses of the study took into account the following main aspects: the influence of the pandemic, the new normality and how they adapted with the online platforms how they view the state implication in this pandemic.

\section{The main results of the research}

There were conducted 10 interviews with artists and cultural entrepreneurs that manage to answer the following three questions as follows. Because of GDPR regulations their name and place of work will not be disclosed. The ten interviews were conducted over the phone, followed by an exchange of many other opinions regarding the pandemic and marketing mix changes that occurred in this time. The three questions asked were:

1. How do you feel about the pandemic and what did you learn from it?

2. What is the new marketing normal for you?

3. What is your opinion regarding the states implication in helping you?

The three questions were meant to better understand the way in which the performing arts were affected by the pandemic and also obtain objective information in relation with this industry from professionals. The way in which the cultural product was sold in these past 10 months has been very different. This challenge has been very interesting to understand from an artists or producers point of view. 


\section{- How do you feel about the pandemic and what did you learn from}

it?

$\mathrm{R} 1$. The pandemic was a challenge, did not expect any of it to be honest. We were preparing for new projects, going on tours, but everything fell apart in February. We knew that we had to change everything up and that is why we started posting on Facebook all our new jams and also even recordings from studios. We started making give-a-ways and also a lot of contests for more user engagement. Yeah...everything changed and I think we all learned that people are social creatures and we really do need social interaction. More than this we need music in our lives cause without it we are extremely depressed.

R2. I learned that it is always good to have a back-up plan. I started some projects last year, but only one stuck. It is very bad. Everything is going from worse to even worse from day to day.

R3. Never ever stay in the same place. Right now I am getting my third album out. This pandemic was good to me. I had some gigs outside, in parks and public places. Indeed, it is difficult with fewer people in the audience, but we wear the masks and play for the legal number of people. Right now it is too cold to sing outside, but we make do with concerts from my living room.

R4. Honestly it was a good time to think outside the box. I got time to paint and get in touch with another side of my work. I learned that we have to give ourselves time even when everything is ok.

R5. Very interesting in creating plays for online and for the public to see the small details that matter. It is a new challenge that I managed to undertake and overcome. I had a lot of success with my actors and singers with two plays. We also tried to do a physical show, but people didn't bought tickets. For the online one in one hour after promoting it on Facebook and Instagram we already sold like 150 tickets.

R6. The pandemic affected me a lot. All of the international projects that I had, crumbled in a matter of months. Years of work and relationship building with partners from all around the world shattered in days even. It was really difficult to see all the efforts my team and I made go away, but we managed to stay afloat. We already were using digital streaming platforms but now we used them a lot more. Also we started doing translations and dubbing for Netflix.

R7. I am neutral to the pandemic. Did learn a lot about people and the psychology of human interaction. The lack of it affects you a great deal. Lack of interaction with loved ones hits hard. To be honest I taught to appreciate more my family, friends and work colleagues.

R8. There is a clear impact. It was difficult in the beginning. Every day I was running around the country with concerts and suddenly it stopped. I learned that nothing lasts and concerts that I had lined up since last year went away in a matter of seconds. Of course it was not their fault, but still it hurt. Right now I am recording an album and couldn't be happier with the time spent with my family.

R9. It didn`t affect me professionally. I went to work, business as usual. It is different from my perspective taking into consideration my position. I have to

95 Review of International Comparative Management

Volume 22, Issue 1, March 2021 
take care of all of my employees. On a personal level yes, it did affect me because nothing is like before.

R10. It was a blessing! I managed to finish my play and was already doing online stuff. I have an online shop with merchandise and in November last year started a stream and had over 1000 subscribers. Now I invite people to my podcast. So yeah, it was good for me.

For the first set of questions we have identified that all 10 respondents have been affected by the pandemic, if not professionally, at least personally. It is very important to note the fact that all respondents understood the fact that the pandemic with all its hardships, offered as well opportunities. Most of the respondents have searched for other services that they could provide.

\section{- What is the new marketing normal for you?}

$\mathrm{R} 1$. My new normal is wearing masks everywhere. Washing my hands 10 times in an hour. Being very careful what I eat and from where I eat it. Ok, from a marketing perspective I guess I always knew social media is playing a big part in bringing people together but right now to be honest I can`t for the life of me understand why I never invested more in it. There are no limitations to audiences and music is universal. So I am investing a lot in our music and after that in placement and ads, communication with our public.

R2. To be honest I really do not care about marketing. But right now I am seeing how online can get you out of a problem really fast. People come together really fast on social platforms.

R3. Cleary talking more to people and getting in contact with other artists from other countries. I did a collaboration with someone from Mexico in August this year. I am using digital platforms like cdbaby and YouTube, I also stream on Instagram, tik-toc and Facebook. Everything is going on online now.

R4. Posting pictures on Instagram, OLX, Facebook and everywhere. I hired my own PR guy who is great and every time we discuss about the message that we put out. Yeah. If you are not online, you don't exist.

R5. Always thinking about my own market and also the extended one. Creating a unique message and going with it on more than one platform because there are different people on different platforms.

R6. The new marketing normal is to use anything that can help me sell tickets or make new contracts. To be honest a lot of influencer have gone under, they are no longer reached by big multi-million companies to sell their products because people right now are oriented towards helping the fellow man, the little man or the little business down on the street where they grew up. I am now using all of my connections to create small communities.

R7. We always think about the main message now and think about other plays that we will have and how to market them under one bigger goal. It is a nice way of creating your own niche market. So yeah, we are thinking on a larger scale and taking into consideration a more market oriented approach because we have to sell tickets online and it is difficult. People are watching and listening from the 
comfort of their own home. We have to reach down to them with our plays on a deeper level. We have to be more honest.

R8. Always thinking of a new product. Approaching the music that I make from the perspective of my consumer, not just my inspiration. I know that promotion is extremely important so that is why I am working with an agency that is specialized in online promotion. I was using Facebook and Instagram, but now I am much more present.

R9. Communication is key. Especially in times of distress and misinformation, we have to communicate. Internal marketing is as important as the external one.

R10. Always thinking about Facebook ads and Google ads. Also I love making video to promote my podcasts on YouTube. It is a whole new world for us right now out there. Too bad a pandemic had to come and change the minds of a lot of people regard using digital marketing for their companies.

For the second questions all respondents agree with the fact that communication and digital marketing is key to be successfully and have a growing community. Social distancing is one of the biggest threats and liabilities with cultural services because it is one of the variables that offer satisfaction to the customer and also a sense of belonging to a certain type of group. This is why artists and managers now are searching for a much more personal approach with consumers, staying connected with them through e-events and social media in order to grow the community and create a sense of belonging.

- What is your opinion regarding the State implication in helping you?

R1. To be honest I know nothing about the states implication.

R2. Yes, the unemployment helped a lot. Also my bosses were very good and digitally oriented. So yeah, they did well on all areas.

R3. I don't know anything about this.

R4. I think I heard about something regarding unemployment and $75 \%$ of something.

R5. Have no clue.

R6. I think they did alright. Maybe they could have done more, but always in hindsight we can improve.

R7. Yeah. A lot. They helped a lot. From the municipal council, from the government, my own bosses. Yeah. They did well with the whole pandemic craziness.

R8. No clue.

R9. Yeah I benefit from the unemployment because I had intellectual property contract before the covid pandemic began.

R10. No help and to be honest they couldn't help us. Maybe lay off the theaters and restaurants because very few people got sick from them...

The third question was important to ask because in 2021 the State Aid Scheme will become available and it was interesting to see if people have

97 Review of International Comparative Management

Volume 22, Issue 1, March 2021 
heard of this plan. Furthermore, it is important to understand the state of mind of the culture professionals regarding the implication of the state and how protected they feel. At the moment, they feel unprotected and that the cultural industry was not entirely left with no help, but clearly there could have been more ways of investing and helping this industry.

Only two respondent benefited from the unemployment state aid so one conclusion could be the fact that this campaign was not communicated efficiently.

All of the professionals that responded to the questions also opened a lot of other topics regarding the pandemic and the fact that it would have been a very good investment from the state to offer funds for online cultural events, creating digital courses for vocational occupations, giving grants to cultural companies etc. Also they mentioned the need to clarify the message that any performing artist or entrepreneur may want to communicate to the public about a cultural service. Before the pandemic people were researching on the internet everything but also were exposed to television, radio and outdoor marketing, but right now the outdoor is no longer viable, or not as viable as before. This leads to an increase in research on the internet and this is why the message should be very easy to understand and clear. Also, there are some of them that managed to buy space on the radio and television to promote some cultural activities at a good price.
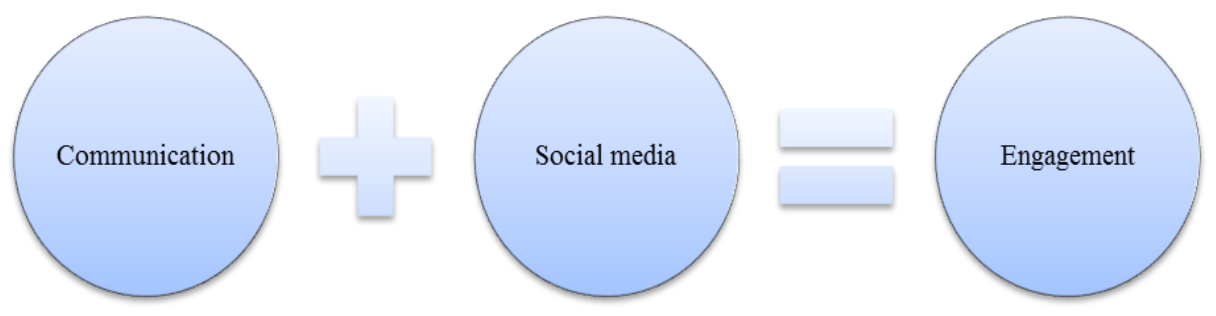

Figure 2 Communication engagement Own representation

One of the most important elements that have changed in this pandemic are:

- Understanding much better the need of the target audience for collective satisfaction and social engagement;

- Opening more ways of communication with the public - feedback has become the bedrock of cultural services;

- Being present on social media and platforms, keeping the audience engaged with free events and paid events;

- Giving back to society - a lot of charity has taken place in the past 8 months, helping people that had a very hard time;

- Communicating efficiently, faster and better with the target audience. 


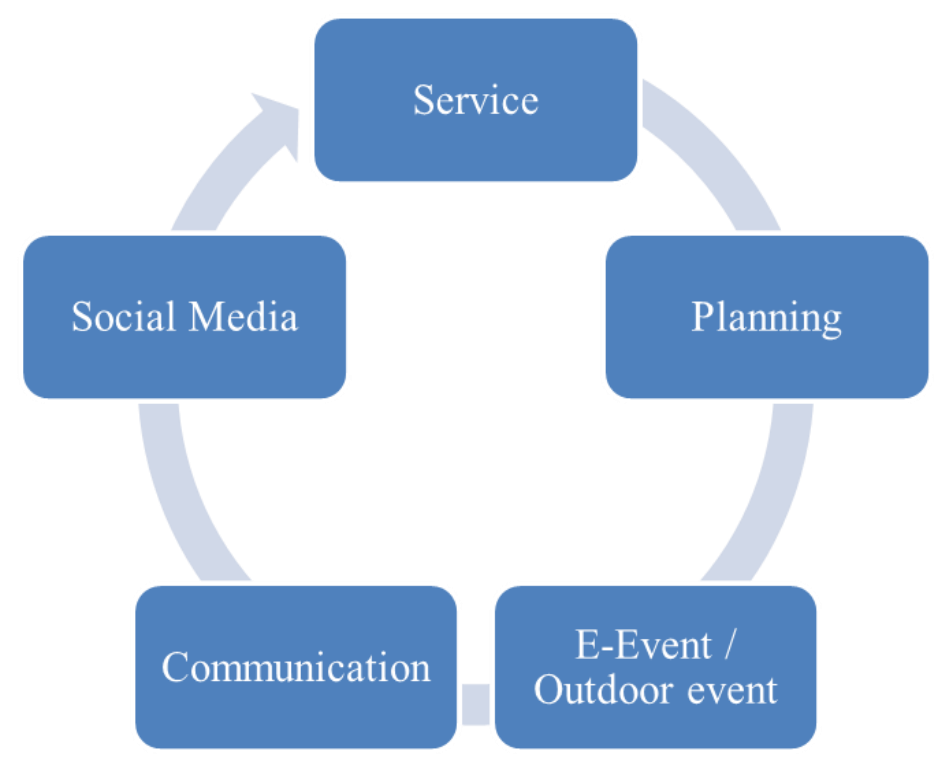

Figure 3 Communication workflow Own representation

The chart above simplifies the answers that professionals have gathered in the last 8 months of the pandemic. The workflow is interesting and functional because it is presented as a cyclical activity that cultural industry professionals have to take into consideration. It also represents the main focus of the discussion in relation with the satisfaction and feedback of the target audience, without it there would be no e-events or outdoor events. Social distancing has been surpassed with the creativity of marketing professionals in the cultural industry sector with the help of digital platforms and creating the feeling of being part of the group, a collective that has the same interests and pleasures as one individual. The feeling of collective acceptance and satisfaction is very important for a successfully service.

\section{Conclusions}

The pandemic was a very big disruptor this year. It managed to change the mentality and habits of consumers. Not only this, but the work environment and cultural organization of companies changed. A lot of people have changed jobs or started new careers. The market shifted and people are now feeling the need to support small family businesses.

Artists and entrepreneurs were pushed towards innovation. The usage of social media platforms and streaming platforms increased. Also for everybody it is clear that having a clear cross-platform message could mean the difference between selling 100 tickets or 1000. Apart from the message, one of the most important aspects is engaging with consumers through content: video and photo. It

99 Review of International Comparative Management

Volume 22, Issue 1, March 2021 
is clear that marketing efforts became much more important with this pandemic with an increase in using digital tools like social media and streaming platforms. Good to take into consideration are the facts that: the cultural product sold still has to have a high quality and the way in which is presented should appeal to more than just one market.

One limit of this research was the lack of physical interaction with the respondents due to Covid 19 restrictions and social distancing. This could be an issue because there was a lack of non-verbal analysis of the respondents.

Another limit is the fact that there is a lack of research on the impact of the pandemic on the cultural arts. There are impact studies on various industries, but there is no clear picture yet of the damage dealt by the pandemic to the performing arts for example from an economic and social perspective: losses, jobs lost, projects that did not make the deadlines, unspent budgets etc.

Some suggestions that we have to better understand and help the cultural industries are based on two levels:

- For the State and the State Aid Scheme they are providing starting with 2021 it should be very important to have active discussions with the entities that provide cultural services in order to better understand their needs. Many time good ideas are met with useless areas of investment or bad ways of implementation.

- For the artists it would be wise to establish a clear message that they would like to communicate to their target audience and make them resonate with it. Start creating the brand behind the service that it is provided. Very important to continue with social responsibility campaigns. Artists have a voice and it should be used for the greater good and to help other people.

- For the managers it would be a great idea to start discussions with other cultural managers in other countries and cities to create online events - music or theater - in partnership with local cultural entities. Create e-festivals that could benefit not just hundreds of thousands, but tens of millions across the EU.

\section{References}

1. Cetină I., Cristache, S. și Bădin, A. 2020. The attitude of the Romanian artists regarding the promotion of the artistic act, JRISS, Vol. 2, Issue 1, pp. 73-83

2. Cuadrado, G. și Deseais A. 2000. La relacion consumidor-artes un equilibrio entra satisfaccion de necesidades y libertad creativa, Estudios Sobre Consumo, Nr. 53, pp. 23-32

3. Europa Direct 2016. Culture statistics 2016, Luxembourg Publications Office of the European Union. Retrieved from http://ec.europa.eu/eurostat/en/web/productsstatistical-books/-/KS-04-15-737

4. Flories, J., Perez, M. and Blanco, V. 2010. El marketing de la cultura y las artes: una evolucion, Revista Nacional de Administracion, Vol. 1(1), pp. 23-36

5. Jimenez, L. \& Gervilla M. 2011. Manual de marketing y comunicacion cultural, Universidad de Cadiz, Cadiz, Espana

6. Mucică, D., Becut, A., Bălşan, B., Croitoru, C., Ionică, P., Nițulescu, V. \& Oprea, A. 2014. Strategia Sectorială în Domeniul Culturii și Patrimoniului Național pentru perioada 2014-2020, Centrul de Cercetare și Consultanță în Domeniul Culturii, pp. $31-473$ 
7. Vukovic, K., Fojs, I. \& Detelj, K., 2019, Entrepreneurs in creative industries: the reconciliation of artistic and commercial logic, Proceedings of INTCESS, Dubai, U.A.E.

8. Scheff, J \& Kotler, P. 1996. Crisis in the arts: The marketing response, California Management Review Vol. 39, pp. 30-50

9. Tătar-Vîstraș, I. 2019. Cultural managers on cultural management practices in Romania, Studia UBB Dramatica, LXIV, 1, pp.11-30

10. Thorsby, D. 2010. The Economics of Cultural Policy, Cambridge niversity Press, Cambridge

WEB: accessed on 12 of november

https://ec.europa.eu/info/live-work-travel-eu/coronavirus-response/jobs-and-economyduring-coronavirus-pandemic_ro accessed on 8 of November 09:37

http://statistici.insse.ro:8077/tempo-online/\#/pages/tables/insse-table accessed on 8 of November 12:44

http://www.cultura.ro/100-milioane-de-euro-pentru-sectorul-cultural-prin-schema-deajutor-de-stat accessed on 8 of November 10:36 